\title{
Evaluation of Different Methods for Considering Bar-Concrete Interaction in Nonlinear Dynamic Analysis of RC Frames by Using Layer Section Theory
}

\author{
${ }^{1 *}$ SEYED SHAKER HASHEMI; ${ }^{2}$ MOHAMMAD VAGHEFI \\ Civil Engineering Department.,Faculty of Engineering, Persian Gulf University, Bushehr, Iran. \\ Email: sh.hashemi@pgu.ac.ir \\ Civil Engineering Department.,Faculty of Engineering, Persian Gulf University, Bushehr, Iran. \\ Email:vaghefii@pgu.ac.ir \\ * Corresponding Author, Tel: + 98771 4222150, Fax: + 987714540376 \\ Email: sh.hashemi@pgu.ac.ir
}

\begin{abstract}
In this paper, the bond-slip effect has been applied to the numerical equations in the process of nonlinear dynamic analysis of reinforced concrete frames. The formulation is similar to that of the layer section theory, but the perfect bond assumption has been removed. The precision of the proposed method in considering the real nonlinear behavior of reinforced concrete frames has been compared to the precision of two other suggested methods for considering bond-slip effect in layer model. Among the capabilities of this method for seismic analysis are its ability of modeling the embedded lengths of bars within joints and nonlinear modeling of bond-slip. The precision of the analytical results were compared with the experimental ones achieved from a one bay two storey frame under seismic loading on the shaking table. According to the numerical results, the presence or absence of bond effect in numerical modeling and analysis will bring about considerable different results, including results for deformation and forces. All the studied methods for inserting the bond-slip effect into the layer model can relatively improve the accuracy of analytical results compared to experimental ones. The proposed method of this study has proved to enjoy the highest accuracy with regard to time-history seismic analysis of reinforced concrete frames. Among the capabilities of the proposed method, we may refer to its ability to model beam-column and joint element's nonlinear behavior separately. @JASEM
\end{abstract}

Keywords: Bond-slip effect, Pull-out effect, Dynamic analysis, Seismic analysis, RC frames

One of the most commonly used methods for nonlinear analysis of RC frames is the layer model that represents the cross section of each frame member as a set of small filaments with finite length and in series along the element. In some of researches this model named fiber method or fiber theory. In this theory the constitutive relation of the section is carried out by integration of the response of the filament, based on uni-axial constitutive law that represents the behavior of concrete or steel. This method assumes perfect bond between concrete and bar (Spacone et al., 1996; Mazars et al, 2006), but this assumption is not very appropriate and realistic and causes a considerable difference between analytical and experimental results (Kwak and Kim, 2006). Belarbi and Hsu (1994) as well as Kwak and Kim (2006) have made use of the fiber method but, in order to modify it and reduce the error of analysis resulted from the perfect bond assumption, they have drawn on an equivalent method. Limkatanyu and Spacone (2002), have used the layer model, but they have removed the perfect bond assumption.

This modified method has been used for beamcolumn elements in this study. But, for modeling reinforced concrete frames, a joint element is also needed. What matters is the compatibility and assimilability of joint elements with beam-columns elements. In initial methods of nonlinear analysis of reinforced concrete frames, the nonlinear effect of beam-column joints is considered using calibration of plastic hinges within adjacent beam-column elements. In such a situation, the joint element is not modeled separately. Based on another approach, the behavior of each of the elements of joint, beam and column is separated. The zero-length rotational spring is one such joint element which need strong calibration process (Alath and Kunnath, 1995). In some newer methods, joint elements are modeled as two-dimensional planes. These elements, however, like finite elements methods, increase the modeling time and the amount of calculations. Another type of joint elements is created by assembling a series of one-dimensional components whose calibration is carried out through experimental results (Lowes et al., 2004). Because force-deformation relations are calculated approximately, such modeling will not be completely precise and will need strong calibration.

In the present study, the beam-column element introduced by Limkatanyu and Spacone (2002) has been used for modeling beam and column elements. Also, a joint element has been defined and used which, in addition to its flexibility in modeling different type of joint elements such as interior, exterior, corner and footing, is capable of being assembled with the above beam-column element (Hashemi et al., 2009). For simplicity's sake, RCF, RCMRF, BCE, and JE will be used instead of reinforced concrete frame, reinforced concrete moment resisting frame, beam-column element and joint element, respectively.

NONLINEAR DYNAMIC ANALYSIS OF RCF: For the purpose of nonlinear analyzing of RCFs and evaluating the proposed method, four kinds of analyses have been examined, as shown in Table 1 . In order to carry our investigations, a computer program created in MATLAB software was used by the authors. 
Description of analyze 1: In this type of analysis, which is a nonlinear analysis using the layer model, the JE is not modeled. Formulation of each RC beam or column element is done based on the EulerBernoulli beam theory. The cross section of the BCE is divided into a suitable number of concrete and steel fibers (bars). In this analysis, the possible slip effect of the longitudinal bar is ignored. Since if the bar slips, the value of the longitudinal strain of the bar will not be the same as the value obtained through the above method; this is the main assumption in the layer model and is referred to as the perfect bond assumption.

Table1: Details of Analysis 1 to 4

\begin{tabular}{|c|c|c|c|c|c|c|}
\hline & & \multicolumn{5}{|c|}{ Nonlinear modeling } \\
\hline & & \multirow{2}{*}{$\begin{array}{l}\text { Modeling } \\
\text { of BCE }\end{array}$} & \multirow{2}{*}{$\begin{array}{l}\text { Modeling } \\
\text { of JE }\end{array}$} & \multicolumn{2}{|c|}{$\begin{array}{l}\text { Applying bond-slip effect } \\
\text { in calculations }\end{array}$} & \multirow{2}{*}{$\begin{array}{l}\text { Applying } \\
\text { pull-out } \\
\text { effect in } \\
\text { calculations }\end{array}$} \\
\hline & & & & $\begin{array}{c}\text { Indirectly as an } \\
\text { equivalent } \\
\text { method }\end{array}$ & directly & \\
\hline $\begin{array}{c}\text { Analysis } \\
1\end{array}$ & $\begin{array}{l}\text { Nonlinear analysis using layer model } \\
\text { and perfect bond assumption }\end{array}$ & Yes & No & No & No & No \\
\hline $\begin{array}{l}\text { Analysis } \\
\quad 2\end{array}$ & $\begin{array}{l}\text { Nonlinear analysis using layer model } \\
\text { and applying bond-slip effect by } \\
\text { modifying yield point in stress-strain } \\
\text { behavior of the bars }\end{array}$ & Yes & No & Yes & No & No \\
\hline $\begin{array}{l}\text { Analysis } \\
\quad 3\end{array}$ & $\begin{array}{l}\text { Nonlinear analysis using the layer } \\
\text { model and applying bond-slip effect } \\
\text { by modifying the yield point and } \\
\text { elasticity modulus in the stress-strain } \\
\text { behavior of the bars }\end{array}$ & Yes & No & Yes & No & No \\
\hline $\begin{array}{c}\text { Analysis } \\
4\end{array}$ & $\begin{array}{l}\text { Nonlinear analysis using proposed } \\
\text { method in this study }\end{array}$ & Yes & Yes & No & Yes & Yes \\
\hline
\end{tabular}

Table2. Selected models for material behavior and their interactions

\begin{tabular}{|c|l|}
\hline \multicolumn{1}{|c|}{ Relationship } & \multicolumn{1}{|c|}{ Description } \\
\hline Concrete stress-strain & $\begin{array}{l}\text { Park et al. (1972) and later extended by Scott et al. } \\
(1982) \text { for monotonic compressive envelope curve } \\
\text { it is assumed that concrete behavior is linearly } \\
\text { elastic in the tension region before the tensile } \\
\text { strength and beyond that, the tensile stress } \\
\text { decreases linearly with increasing tensile strain } \\
\text { Yassin (1994) rules is adopted for hysteresis } \\
\text { behavior }\end{array}$ \\
\hline Steel stress-strain & $\begin{array}{l}\text { The initially proposed model by Giuffre and Pinto } \\
(1970) \text { and later used by Menegoto and Pinto } \\
(1973)\end{array}$ \\
\hline Bond stress-bond slip & Eligehausen et al. (1983) model \\
\hline Shear stress-shear deformation in the JEs & Anderson et al. (2008) model \\
\hline
\end{tabular}

Table3: Comparing of the analytical results with the experimental one for the tested specimen

\begin{tabular}{|c|c|c|c|c|}
\hline & \multicolumn{3}{|c|}{ comparison of experimental and analytical results (relative error percentage) } \\
\cline { 2 - 5 } & Analyze 1 & Analyze 2 & Analyze 3 & Analyze 4 \\
\hline $\begin{array}{c}\text { Maximum lateral displacement at level } \\
\text { of top storey }\end{array}$ & -24.12 & -15.29 & -7.06 & -6.81 \\
\hline Maximum drift of second storey & -43.38 & -23.29 & -4.11 & -3.5 \\
\hline Maximum of base shear & +15 & +7.5 & +3.77 & +2 \\
\hline
\end{tabular}

Description of analyze 2: This analysis is very similar to analysis 1 and is in fact a layer model, but for the purpose of reducing errors induced by the perfect bond assumption, the analysis is modified into a yielding point equivalent in the bar stress-strain diagram of a nonlinear solution. If the yielding point stress of the bar obtained from tensile tests without concrete is $\sigma_{y}$, the yielding point of the bars will be lower than $\sigma_{y}$ and will be used in numerical calculations. Based on this theory and research done by Belarbi and Hsu (1994), the bar stress-strain equation is modified into equation 1 .

$$
\left\{\begin{array}{l}
\sigma_{s}=E_{s} \cdot \varepsilon_{s} \quad: \varepsilon_{s} \leq \varepsilon_{n} \\
\sigma_{s}=\sigma_{n}+\left(0.02+0.25 B_{B}\right) E_{s}\left(\varepsilon_{s}-\varepsilon_{n}\right), B_{B}=\left(f_{t} / \sigma_{y}\right)^{l .5} / \rho \\
, \varepsilon_{n}=\varepsilon_{y}\left(0.93-2 B_{B}\right) \quad: \varepsilon_{s} \geq \varepsilon_{n}
\end{array}\right.
$$


In the above equations, $\mathcal{E}_{s}$ and $\sigma_{s}$ are the bar strain and stress, respectively. $\varepsilon_{y}$ and $\sigma_{y}$ are the bare bar yielding point strain and stress, respectively. And $f_{t}$ is the tensile strength of the concrete. $\rho$ is the ratio of the bar cross sectional area to the cross sectional area of the whole RC section, which must be more than 0.005 .

Description of analyze 3: For the purpose of reducing errors induced from the perfect bond assumption, in this type of analysis the yield stress of the bars is modified into an equivalent value as described in analysis 2 . But here, not only the yielding point but also the bar elasticity modulus are modified. Based on the function of slip distribution between cracks and assuming a linear relationship between slip and bond-stress, the axial force balance of a concrete length segment and of adjacent bars is studied, and the axial force is appropriately divided between the bar and the adjacent concrete, thereby creating a balance. Finally, in this type of analysis an equivalent elasticity modulus will be used for the steel bars. For more information regarding the numerical calculation of the equivalent elasticity modulus and using this calculation in layer model analyses, please, see (Kwak and Kim, 2006).

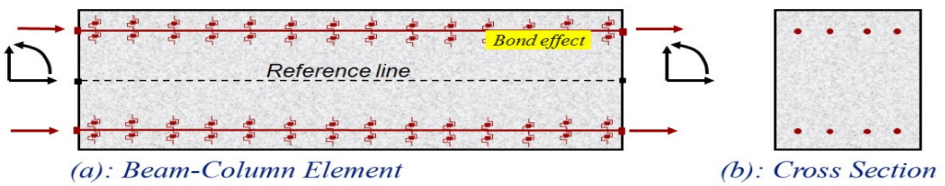

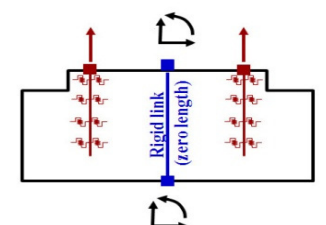

(c): Joint Element Type 1

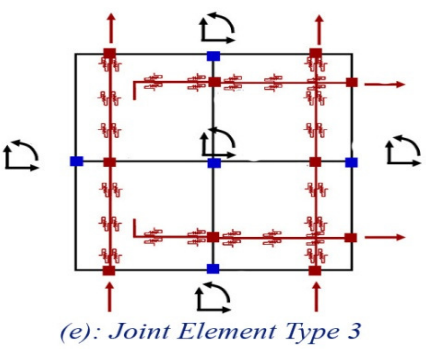

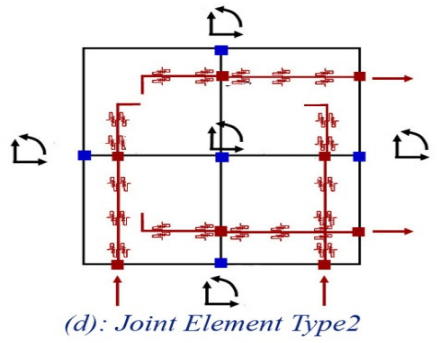

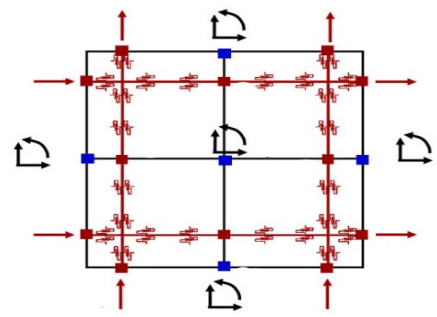

(f): Joint Element Type 4

Fig 1: Details for modeling of BCE and JEs in the analyze 4

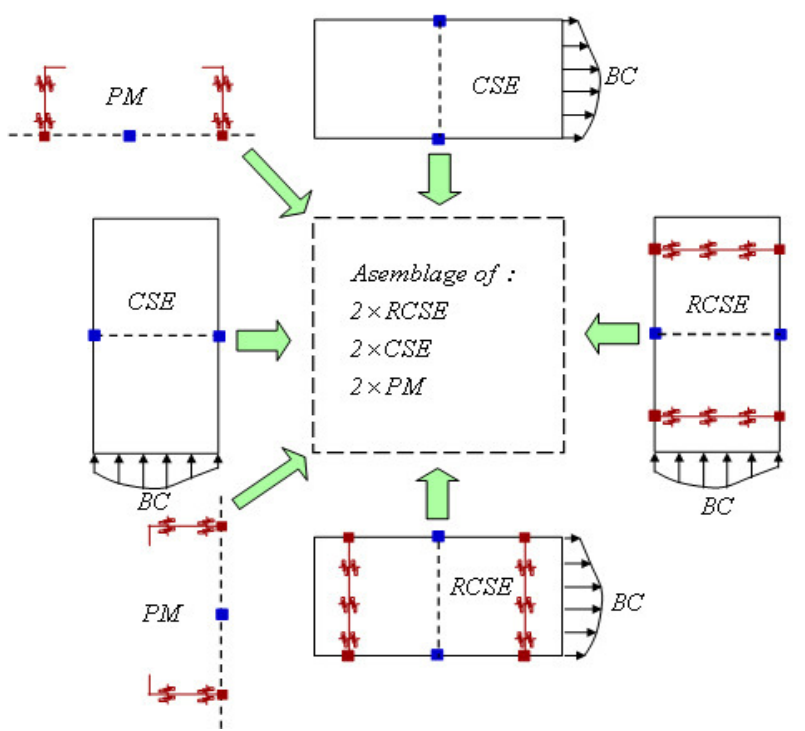

Fig 2. Details of assembling in the modeling of the type 2 of JEs 


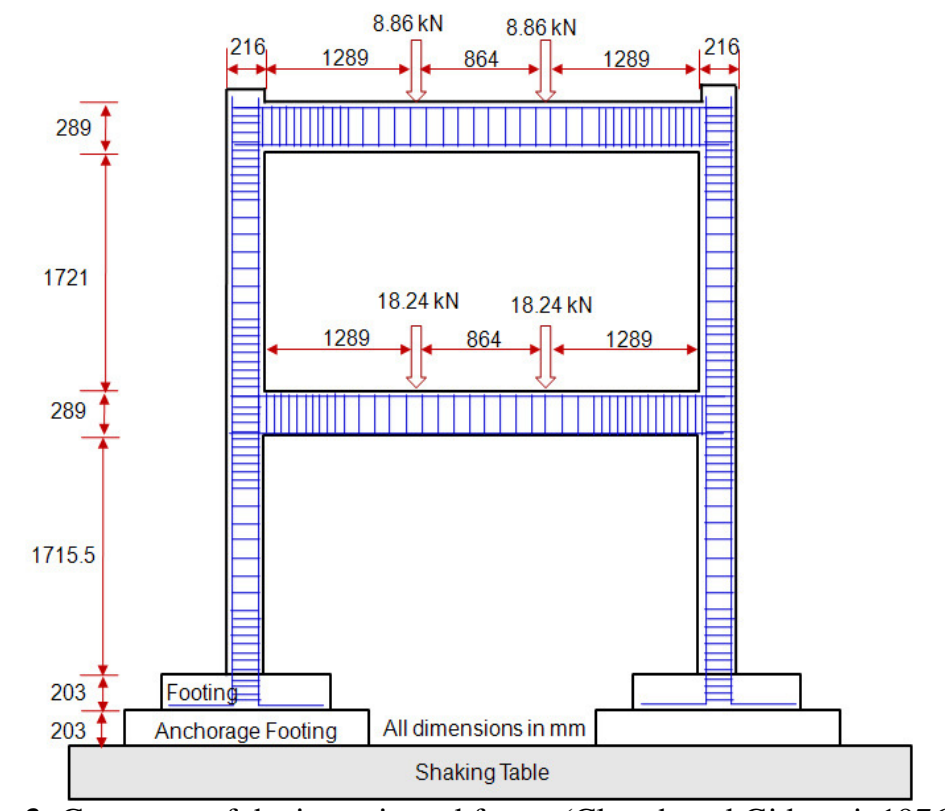

Fig 3: Geometry of the investigated frame (Clough and Gidwani, 1976)

Description of analyze 4: In this kind of analysis, both of BCE and JE have been modeled. Depending on the position of the joint in the RCF, four types of joint can be defined. For modeling a BCE based on research carried out by Limkatanyu and Spacone (2002), in the layer model, the slip effect between concrete and bar is implemented without ignoring the compatibility of the strain between concrete and bar. In this method, a length segment of an $\mathrm{RC}$ frame element is considered as a combination of a length segment of a 2-node concrete element and a number of steel bar elements (i.e., longitudinal bars). 2-node concrete elements follow the Euler-Bernoulli theory, and 2-node bar elements are in fact trusses elements. Contact between concrete and the longitudinal bars are provided by a constant bond force around the bars. Using the internal forces balance equations, the governing equations of the length segment of the BCE are obtained. A weak form of the governing equation in a finite elements method is obtained using the shape functions based on displacement and using the principle of stationary potential energy. More information on this element can be found in (Limkatanyu and Spacone, 2002) (Figure 1-a\&b). For the sake of simplicity in modeling of different types JEs, at first, a reinforced concrete sub-element, a concrete sub-element and a bar pull-out mechanism are defined which for simplicity's sake, RCSE, CSE and PM will be used instead of them respectively. The RCSE and CSE follow the Timoshenko beam theory. These sub-elements are capable of considering shear deformation and bond-slip effects in nonlinear behavior. According to the location of the JEs in a two dimensional RCF, four types of element is defined. Type 1 of JEs is basically modeled on PM and rigid links that simulate the behavior of footing connections (Fig. 1-c). Type 2 of JEs is used as the substitute of the corner connection in the frame, embracing two RCSEs, two CSEs, and two PMs (Fig. 1-d). These parts are assembled according to Figure 2 and the effect of boundary conditions (BC) is considered on the specified side sections based on the results of internal forces in the related sections during analysis. Type 3 , which can be used as an exterior connection in the frame, is the assemblage of three RCSEs, one CSE, and one PM (Fig. 1-e). Type 4 is a representative of an interior connection in which the PM is not considered because all longitudinal bars have been passed through the element. This type is a combination of four RCSEs (Fig. 1-f). More information on about JE can be found in (Hashemi et al., 2009).

Behavior of materials: Behavior of materials selected as Table 2.

NUMERICAL ANALYSIS: A one bay two storey frame have been studied and analytic results have been compared with corresponding experimental ones. This specimen was tested by Clough and Gidwani in 1976 on a shaking table affected by a component of the real acceleration record of the Arvin-Tahchapi earthquake scaled for $P G A=0.57 \mathrm{~g}$. This frame is modeled as the combination of BCEs, JE type 1, 2 and type 3. Some details of that are shown in Figure 3 and more details are given in (Clough and Gidwani, 1976). Newmark's method has been used for solving the equation of motion in the numerical investigation, and the equation of motion has been solved incrementally. Acceleration changes have been considered constant in each time step and parameters $\beta=0.25$ and $\gamma=0.5$ have been used. Rayleigh's damping matrix has been taken and the damping coefficient $\xi$ has been assumed $3 \%$. The $P-\Delta$ effects have been considered in a nonlinear analysis. In Figure 4, the lateral displacement in the second 
Evaluation of Different Methods for Considering.... storey level calculated in the four previously defined analyses, have been compared with the corresponding experimental results. Table 3 shows a comparison of experimental and analytical results, including the results for the levels' lateral displacement and base shear and drift. In this comparison, a relative error percentage with a plus sign $(+)$ reveals a higher value for the analytical result compared to experimental, and a minus sign (-) reveals a lower one. Based on the results, if the bond effect is excluded, analytical and experimental results will be considerably different (analysis 1). Including the equivalent bond effect (analyses 2 and 3) leads to more accurate results, but as shown in Figure 4, there is still no good agreement between analytical and experimental figures. The use of proposed method (analysis 4) results into more accurate answers and a better agreement between analytical and experimental figures.
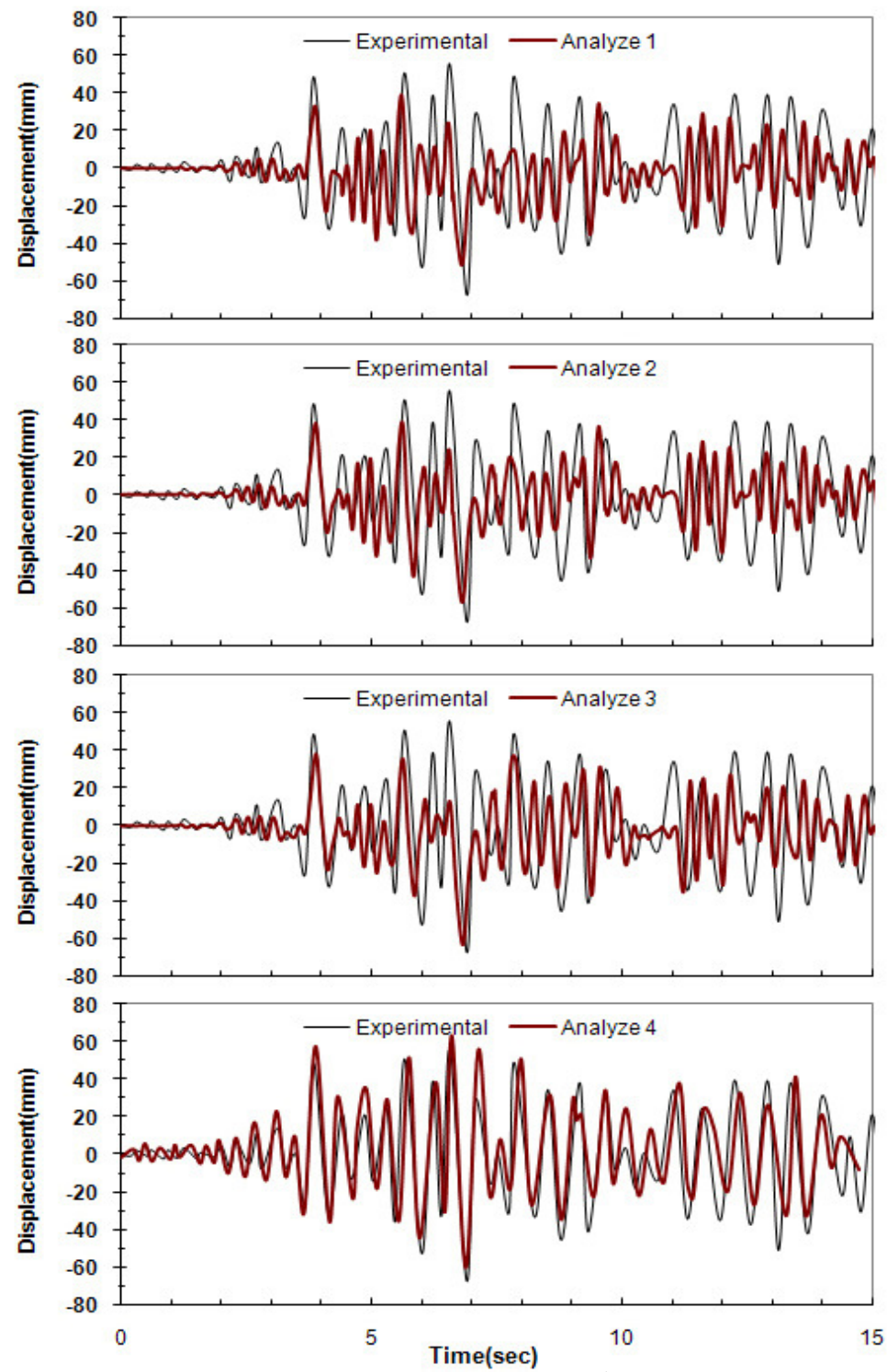

Fig 4: Experimental and analytical time history of the $2^{\text {nd }}$ storey's lateral displacement

Conclusion: According to the results, the presence or absence of bond effect in numerical modeling and analysis will bring about considerable different results, including results for deformation and forces. All the studied methods for inserting the bond-slip effect into the layer model can relatively improve the accuracy of analytical results compared to experimental. The proposed method of this study has proved to enjoy the highest accuracy with regard to time-history seismic analysis. Among the capabilities of the proposed method, we may refer to its ability to model beam-column and JEs' nonlinear behavior separately. Finally, the authors of this paper suggest this method will be useful and remarkably accurate for nonlinear dynamic analysis of RCMRF.

\section{REFERNCES}

Alath, S; Kunnath, SK (1995). Modeling inelastic shear deformation in RC beam- column Joints. Engineering mechanics: Proceedings of 10th conference, University of Colorado at Boulder, 
Evaluation of Different Methods for Considering.... Boulder, Colorado, May 21-24, Vol. 2. New York, ASCE, pp 822- 825.

Anderson, M; Lehman, D; Stanton, J (2008). A cyclic shear stress-strain model for joints without transverse reinforcement. Engineering Structures, 30:941- 954.

Belarbi, A ; Hsu, TTC (1994). Constitutive laws of concrete in tension and reinforcing bars stiffened by concrete. ACI Structural Journal, 91(4): 465474.

Clough, RW; Gidwani, J (1976). Reinforced concrete frame 2: seismic testing and analytical correlation. Earthquake Engineering Research Center, Report no. EERC 76-15. Berkeley (CA): Univ. of California.

Eligehausen, R; Popov, E; Bertero, V (1983). Local bond stress-slip relationship of deformed bars under generalized excitations. Report No. UCB/EERC-83/23, Earthquake Engineering Center, University of California, Berkeley.

Giuffre, A; Pinto, PE (1970). Il Comportamento del cemento armato per sollecitazzioni cicliche di forte intensita. Giornale del genio civile, Maggio.

Hashemi, S SH; Tasnimi, A; Soltani M (2009). Nonlinear cyclic analysis of reinforced concrete frames, utilizing new joint element. Scientia Iranica Journal, 16(6): 490-501.

Kwak, HG; Kim, JK (2006). Implementation of bond-slip effect in analyses of RC frames under cyclic loads using layered section method. Engineering Structures, 28: 1715-1727.

Limkatanyu, S; Spacone, E (2002). Reinforced concrete frame element with bond interfaces. part I: displacement-based, force-based, and mixed formulations. Journal of Structural Engineering, ASCE, 128(3): 346- 355.
Lowes, LN; Mitra, N; Altoontash, A (2004). A beam-column joint model for simulating the earthquake response of reinforced concrete frames. Report No. 2003/10, Pacific Earthquake Engineering Research Center (PEER).

Mazars, J; Kotronis, P; Ragueneau, F; Casaux, G (2006). Using multifiber beams to account for shear and torsion applications to concrete structural elements. Computer Methods in Applied Mechanics and Engineering, 195: 72647281.

Menegoto, M; Pinto, P (1973). Method of analysis for cyclically loaded RC plane frames including changes in geometry and non-elastic behavior of elements under combined normal force and bending. Symp. Resistance and Ultimate Deformability of Structures Acted on by Well Defined Repeated Loads, IABSE Reports, Vol. 13, Lisbon.

Park, R; Kent, DC; Sampton, RA (1972). Reinforced concrete members with cyclic loading. Journal of the Structural Division, ASCE, 98(7): 1341-1360.

Scott, BD; Park, R; Priestley, MJN (1982). Stressstrain behavior of concrete confined by overlapping hoops at low and high strain rates. ACI Journal, 79(1): 13-27.

Spacone, E; Filippou, FC; Taucer, FF (1996). Fibre beam-column model for nonlinear analysis of $\mathrm{R} / \mathrm{C}$ frames: part I. formulation. Earthquake Engineering and Structural Dynamics, 25: 711725.

Yassin, MHM (1994). Nonlinear analysis of prestressed concrete structures under monotonic and cyclic loads. Dissertation. University of California. Berkeley, California. 